\title{
Assessment of district health supervisory system
}

Pakistan Initiative for Mothers and Newborns (PAIMAN)

Follow this and additional works at: https://knowledgecommons.popcouncil.org/departments_sbsr-rh

Part of the Family, Life Course, and Society Commons, and the Maternal and Child Health Commons How does access to this work benefit you? Let us know!

\section{Recommended Citation}

Pakistan Initiative for Mothers and Newborns (PAIMAN). 2006. "Assessment of district health supervisory system." Islamabad: John Snow Inc (JSI). 
Assessment of District Health

Supervisory System

2006 
The document was made possible through support provided by the United States Agency for international Development (USAID), under the terms of cooperative agreement number 391-A-00-0501037-00 and sub-agreement number 36098-02 for PAIMAN.

The Pakistan initiative for Mothers and Newborns (PAIMAN) is a 6-year USAID funded project designed to reduce country's maternal and neonatal mortality by making sure that women have access to skilled birth attendants during childhood and throughout postpartum period. PAIMAN works at national, provincial and district levels to strengthen the capacity of public and private health care provider and improve health care system. The PAIMAN program is jointly implemented by John Snow Inc (JSI), the Contech International, Greeenstar Social Marketing, Johns Hopkins University/CCP, PAVHNA, The Population Council, Save the Children USA.

Copyright @ 2006 by John Snow Inc (JSI). All Rights Reserved

\section{Published by:}

PAIMAN (Pakistan Initiative for Mothers and Newborns)

House 6, Street 5, F-8/3, Islamabad, Pakistan

Chief of Party-PAIMAN

Dr. Nabeela Ali

For inquiries, please contact

\section{Contech International Health Consultants}

2-G Model Town, Lahore, Pakistan

Tel: 042-35888798-99

Fax: 042-35845774

Email: contech@brain.net.pk

Web: www.contech.org.pk

\section{Disclaimer:}

This report is made possible by the generous support of the American people through the United States Agency for International Development (USAID). The contents are the responsibility of JSI Research \& Training Institute, Inc. and do not necessarily reflect the views of USAID or the United States Government." 


\section{TABLE OF CONTENTS}

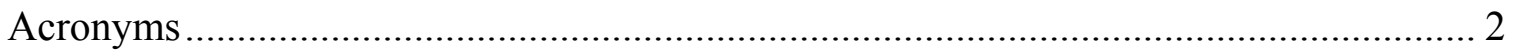

Executive Summary:.............................................................................................. 4

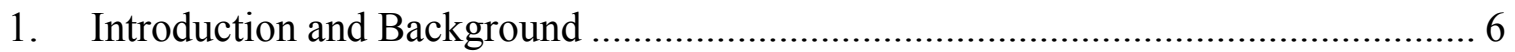

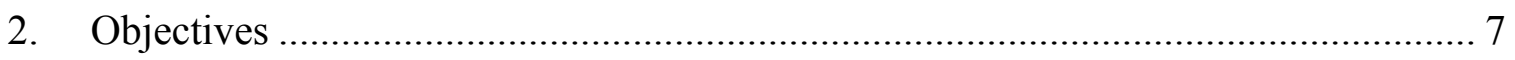

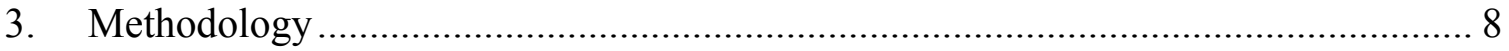

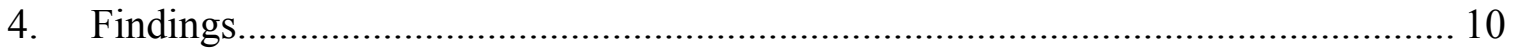

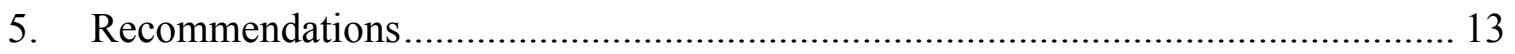

i. Framework for supportive supervision ............................................................. 14

ii. Development/adaptation of Supervisory Checklist ............................................. 14

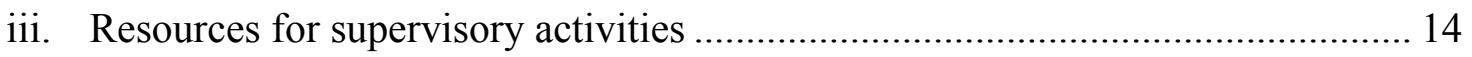

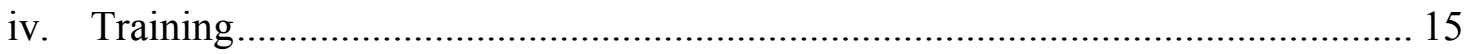

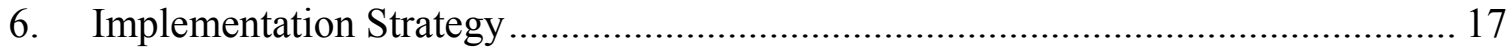

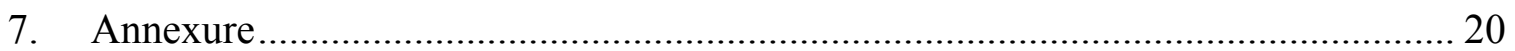

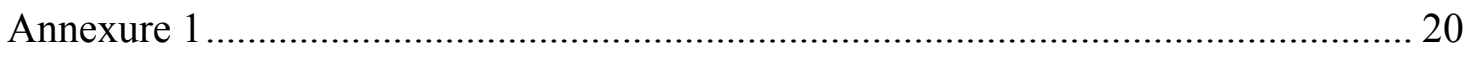

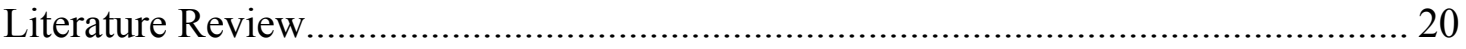

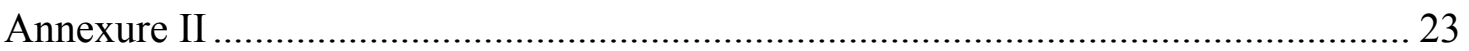

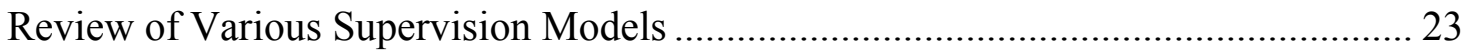

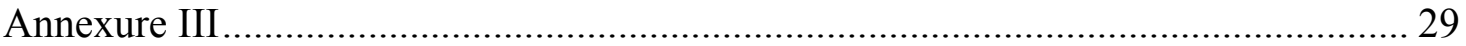

A) Checklists of observations for supervisory visits ............................................... 29

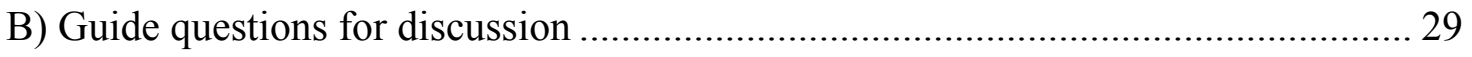

C) Checklist for the review of record ...................................................................... 29

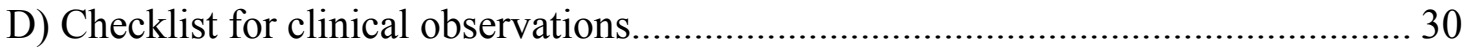

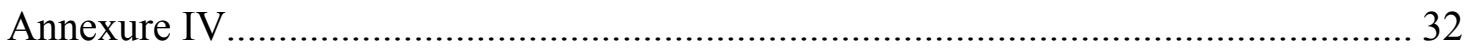

List of Experts Consulted........................................................................................... 32 


\section{Acronyms}

AIDS: $\quad$ Acquired Immune Deficiency Syndrome

AIHC: $\quad$ Assistant Inspectress of Health Centers

AKU: $\quad$ Agha Khan University

ASV: $\quad$ Assistant Superintendent Vaccination

BHU: $\quad$ Basic Health Unit

BP: $\quad$ Blood Pressure

CDC: $\quad$ Communicable Disease Control

CDCI: Communicable Disease Control Inspector

CDCO: Communicable Disease Control Officer

CEO: $\quad$ Chief Executive Officer

DOH: $\quad$ District Officer (Health)

DDHO: Deputy District Health Officer

DGHS: $\quad$ Director General Health Services

DHDC: District Health Development Centre

DHIS: District Health Information System

DHMT: $\quad$ District Health Management Team

DHQ: District Headquarter

DSV: District Superintendent Vaccination

DSI: $\quad$ District Sanitary Inspector

EDO $(\mathrm{H})$ : $\quad$ Executive District Officer (Health)

EPI: $\quad$ Expanded Program on Immunization

HMIS: $\quad$ Health Management Information System

HIV: $\quad$ Human Immune Deficiency Virus

IMR: Infant Mortality Rate

IV: Inspector Vaccination

JSI: John Snow Inc.

LHW: $\quad$ Lady Health Worker 


$\begin{array}{ll}\text { LHS: } & \text { Lady Health Supervisor } \\ \text { MNH: } & \text { Maternal Neonatal Health } \\ \text { MMR: } & \text { Maternal Mortality Ratio } \\ \text { MOH: } & \text { Ministry of Health } \\ \text { MS: } & \text { Medical Superintendent } \\ \text { NGO: } & \text { Non-Governmental Organization } \\ \text { NWFP: } & \text { North West Frontier Province } \\ \text { OPD: } & \text { Outpatient Department } \\ \text { PAIMAN: } & \text { Pakistan Initiative for Mothers and Newborn } \\ \text { PHC: } & \text { Primary Health Care } \\ \text { RHC: } & \text { Rural Health Center } \\ \text { SI: } & \text { Sanitary Inspector } \\ \text { TB: } & \text { Tuberculosis } \\ \text { THQ: } & \text { Tehsil Headquarter } \\ \text { TSI: } & \text { Tehsil Sanitary Inspector } \\ \text { USAID: } & \text { United States Agency for International Development } \\ \end{array}$




\section{Executive Summary:}

The Pakistan Initiative for Mothers and Newborn (PAIMAN) is a five-year project funded by the United States Agency for International Development (USAID). The project is being implemented in 10 districts of the country. Main objective of the project is to reduce maternal, neonatal and children morbidity and mortality in intervention districts. District health system strengthening is one of the strategic objectives with supportive supervision as one of the key element. In order to reinforce supportive supervision, PAIMAN intends to improve \& support implementation of supportive supervision system within the districts. Assessment of the existing supervisory system was considered as first step towards proposing interventions for its improvement.

The supervisory performance assessment was designed to guide the development of the improved supportive supervision system by providing a better understanding of the challenges health supervisors encounter. A variety of qualitative techniques were instituted which included; observations, discussion with supervisors and supervisee and record review, enriched with national and international literature review. Improved system is being proposed in light of the results and recommendations of the assessment.

National and international literature was reviewed; a survey of 5 districts i.e. Jhelum \& Dera Ghazi Khan (Punjab), Buner (NWFP), Dadu (Sindh) and Lasbela (Balochistan) was conducted and observations and informal discussions were held with the supervisors and the supervisee. Finally brainstorming sessions were held with team of public health professionals in order to accomplish the assignment. Key findings and recommendations are given in the following paragraphs.

Although most supervisors define supervision in different ways, commonly mentioned themes or concepts include: "providing guidance," "checking," "monitoring and evaluation" and "ensuring that what needs to be done is done."

It was observed that most health professionals charged with supervision responsibilities in districts lack the full range of knowledge and skills in core competencies to perform their job. Most supervisors neither have received training in these areas nor provided any support for supervision. In addition, other causes of poor performance in supervision include: insufficient funds for transportation, lack/non-use of supervisory tools, infrequent supervision visits and inadequate national and provincial guidelines for effective supervision.

The interventions recommended to improve supervisor's performance include: development of framework for supportive supervision, adaptation/development of supervisory tools, advocacy for provision of essential resources and training. To maximize the effect of making up the deficiencies mentioned above, it is essential that the other causes of poor performance, e.g. operational budgets need to be addressed concurrently. 
An implementation strategy is being proposed to guide the process of implementation of supportive supervision. A Comprehensive Supportive Supervision Model has been proposed having direct, indirect supervision coupled with community participation. The model proposes a methodology to institutionalize the supportive supervision in the existing system in a phased manner. In the first 3 months, all relevant material i.e. policy guidelines, supervisory tools and training package will be developed. In second-offsite training phase, class room training on concept of supportive supervision along with key competencies required for an effective supervisor has been suggested. In the next 4 months, onsite training with the involvement of a "Mentor" is recommended that will involve training in indirect/remote/telecommunication supervision too. Last 6 months out of the whole of 15 months, supervisor will work independently and community participation within all phases of the process will be ensured through involvement of DHMTs and community representatives. After 15 months of implementation, an evaluation will be conducted in order to refine and further improve the system. 


\section{Introduction and Background}

The Pakistan Initiative for Mothers and Newborn (PAIMAN) is a five-year project designed to reduce the country's maternal and neonatal mortality by making sure women have access to skilled birth attendants during childbirth and throughout the postpartum period. Funded by the United States Agency for International Development (USAID), PAIMAN works at national, provincial and district levels to strengthen the capacity of public and private health care providers and to improve health care delivery system. PAIMAN has developed a community-based approach that provides a continuum of care to mothers and newborns through supportive linkages from home care to hospitalbased care. PAIMAN is closely working with Ministry of Health, Provincial Health Departments, and districts.

By the end of the project, PAIMAN envisages a health system in the project area that delivers high quality Maternal and Newborn Health (MNH) services where all levels of health providers work closely with empowered, educated and organized communities.

The PAIMAN consortium is lead by John Snow Inc. (JSI), a US-based international public health organization. JSI is joined by a number of international and Pakistani organizations to form a professional team for implementing this project. The consortium partners are:

- Agha Khan University (AKU)

- Contech International Health Consultants

- Greenstar Social Marketing

- Johns Hopkins University Bloomberg School of Public Health Center for Communication Programs (CCP)

- Population Council (PC)

- The Pakistan Voluntary Health and Nutrition Association (PAVHNA)

- $\quad$ Save the Children U.S.

As per Economic Survey of Pakistan 2005-6, the health care is provided in the public health sector through 916 Hospitals, 552 Rural Health Centres, 5,301 Basic Health Units and 4,582 Dispensaries in the country. At present there are 113,206 doctors in the country, which means there is one doctor for 1,359 persons whereas the number of available dentists in the country is about 6,127 , which give a population-dentist ratio at 25,107 persons per dentist. The number of trained nurses in public health sector is 48,446 , which means, one nurse is available for 3,175 persons. The most notable vertical programs include the LHW program, Expanded Program on Immunization, AIDS Control Program, Malaria Control Program, TB. Control Program, Women Health Project, Nutrition Program, Hepatitis Control Program, Non-communicable disease Control Program, and Population Welfare Program.

Various assessments of the district health system suggest that it suffers from many weaknesses that impair its efficiency, quality and impact. Though government, since independence, adopted various strategies and diverse approaches through successive 
National Health Policies, there is scant improvement in health indicators including population growth rate, MMR, IMR, etc. Certainly there is exhaustive list of management and service delivery issues leading to the current situation. The inefficient and ineffective supervision is one of the most important factors for poor performance of the health sector ${ }^{1}$.

Ongoing supervision is an important, often overlooked, step for ensuring quality health services. While supervision can be a very participatory process, traditional supervisory visits focus more on inspection and fault finding rather than on problem solving to improve performance. Health workers often receive little guidance on how to improve their performance. They are frequently left undirected, with few or no targets to help assess their performance leading to lack of motivation.

Supervisors often lack the skills needed to effectively supervise health facilities across many functions for which they are responsible. The third party evaluation of LHW program, 2001, indicates that there is direct association of supervisor's knowledge and skill with the performance of the $\mathrm{LHWs}^{2}$. In addition to assessing performance, supervisors are also expected to monitor services \& management and ensure that the health facilities are working properly; all in a short period of time. Consequently, they are unable to provide adequate technical guidance and feedback to service providers to improve their performance. An effective supportive supervision with following explicit objectives thus may play a key role to improve the quality of services and lessen the gravity of situation:

- To make sure that operational objectives are appropriate;

- To find out what is being done well;

- To help staff to identify and solve problems;

- To motivate the staff; and

- To improve the skills of the staff.

\section{Objectives}

The supervisory performance assessment was designed to guide the development of the improved supportive supervision system by providing a better understanding of the challenges health supervisors encounter. The assignment aimed to strengthen the quality as well as coverage of health care facilities through improved supervision. The specific objectives of this assignment are:

- To provide a basic description of the existing district health supervisory network;

- To enlist the existing district supervisory tools;

\footnotetext{
${ }^{1}$ Loan 1671-PAK(SF): Women's Health Project, for \$47 million, approved on 16 March 1999

${ }^{2}$ External Evaluation of the LHW program, Summary of Final Report, Oxford Policy Management, March 2002
} 
- To identify gaps in the existing supervisory system; and

- To suggest remedial measures for improved supervision

\section{Methodology}

Out of 10 PAIMAN districts, 5 were randomly selected and it was ensured that at least one district from each province is included in the assessment. Within each district one supervisor was selected for observation while conducting supervisory visits.

\begin{tabular}{|l|l|l|}
\hline \multicolumn{1}{|c|}{ Province } & \multicolumn{1}{|c|}{ District } & Supervisor \\
\hline \multirow{2}{*}{ Punjab } & Jhelum & AIHC \\
\cline { 2 - 3 } & D G Khan & DOH \\
\hline Sindh & Dadu & DDHO \\
\hline NWFP & Buner & LHS \\
\hline Balochistan & Lasbela & DSV \\
\hline
\end{tabular}
Participation from all levels of supervisors was ensured. The selected districts and supervisors are shown in the text table.

Five facilities (see text table), one from each selected district, were visited to observe the quality of $\mathrm{MNH}$ services for identification of areas to be included while suggesting improved supervisory system. In each facility, OPD, operation theater, laboratory, and wards were observed.

\begin{tabular}{|l|l|l|}
\hline \multicolumn{1}{|c|}{ Province } & \multicolumn{1}{|c|}{ District } & \multicolumn{1}{|c|}{ Health Facility } \\
\hline \multirow{2}{*}{ Punjab } & Jhelum & RHC Dina \\
\cline { 2 - 3 } & D. G. Khan & RHC Sarwarwali \\
\hline Sindh & Dadu & BHU Gozo \\
\hline NWFP & Buner & $\begin{array}{l}\text { DHQ hospital } \\
\text { Daggar }\end{array}$ \\
\hline Balochistan & Lasbela & THQ hospital Hub \\
\hline
\end{tabular}

A variety of methods were used to collect the relevant information. The detail is given below:

\section{Literature Review}

Literature review was carried out as ongoing activity for best practices nationally and internationally. Summary of literature review was prepared and placed as Annexure I. A number of supervision models are available in the international literature. The details of different successful supervision models are available at Annexure II.

\section{Observations:}

a. During supervisory visits, observations were focused on following points:

- Availability and use of supervisory tool(s);

- Time spent on supervisory activities;

- Technical competence of supervisors; and

- Verbal feedback and support provided for improvement. 
b. The focus of the clinical observations was on the following areas:

- Patient care and clinical procedures in OPD;

- Case reviews of admitted patients with obstetric complications.

- Case reviews of cured and discharged patients with obstetric complications on the day of visit

\section{Discussion with the supervisors and supervisee}

Supervisors' strengths and weaknesses were assessed through discussion focusing on the following points:

- Definition and concept of supervision;

- Understanding of core tasks;

- Frequency of visits;

- Use of information collected during visit;

- Feedback reports of the supervisory visits to the supervisee;

- Mechanism for monitoring of corrective actions suggested; and

- Supervisory training in the past.

Supervisees were asked whether supervisor's visits were helpful in improving their performance.

\section{Review of Record}

Record relating to supervisory activities of the selected supervisors was also reviewed with focus on following points:

- Schedule of supervisory visits;

- Schedule communicated ahead to the supervisee;

- Filled in supervisory checklists of the previous visits or tour notes; and

- Written feedback reports.

\section{Consultations with public health experts}

Eminent public health experts were consulted, findings were discussed and recommendations were formulated in line of their expert opinion. List of experts consulted is available at Annexure IV.

Data collection was carried out from June through July 2006 (the checklists used for data collection is available at annexure III). The research team conducted meetings after completion of the study with selected supervisors in order to enrich the interpretation of the findings and to develop intervention strategies for improving the supervision process. 


\section{Findings}

The findings are being presented in the following paragraphs based on observations, discussion and review of record.

The health services delivery system in Pakistan is a mix of public and private providers. In the public sector federal and provincial governments operate tertiary care hospitals in larger urban areas. In towns and rural areas, the district governments operate an extensive infrastructure of primary and secondary health care facilities supported by several federal/provincial programs. The government is by far the major provider of health care in rural areas, and it is also the main provider of the preventive care throughout the country.

The district health department in Pakistan is organized on a similar pattern in each district with slight variation across the provinces and is headed by Executive District Officer Health (EDO-H). S/He is assisted by number of officials to effectively manage the district health department. At tehsil/taluka level, DDHO is responsible for management of the public health sector except in NWFP where there is no Tehsil tier. Prototype organogram of district health department is given below:

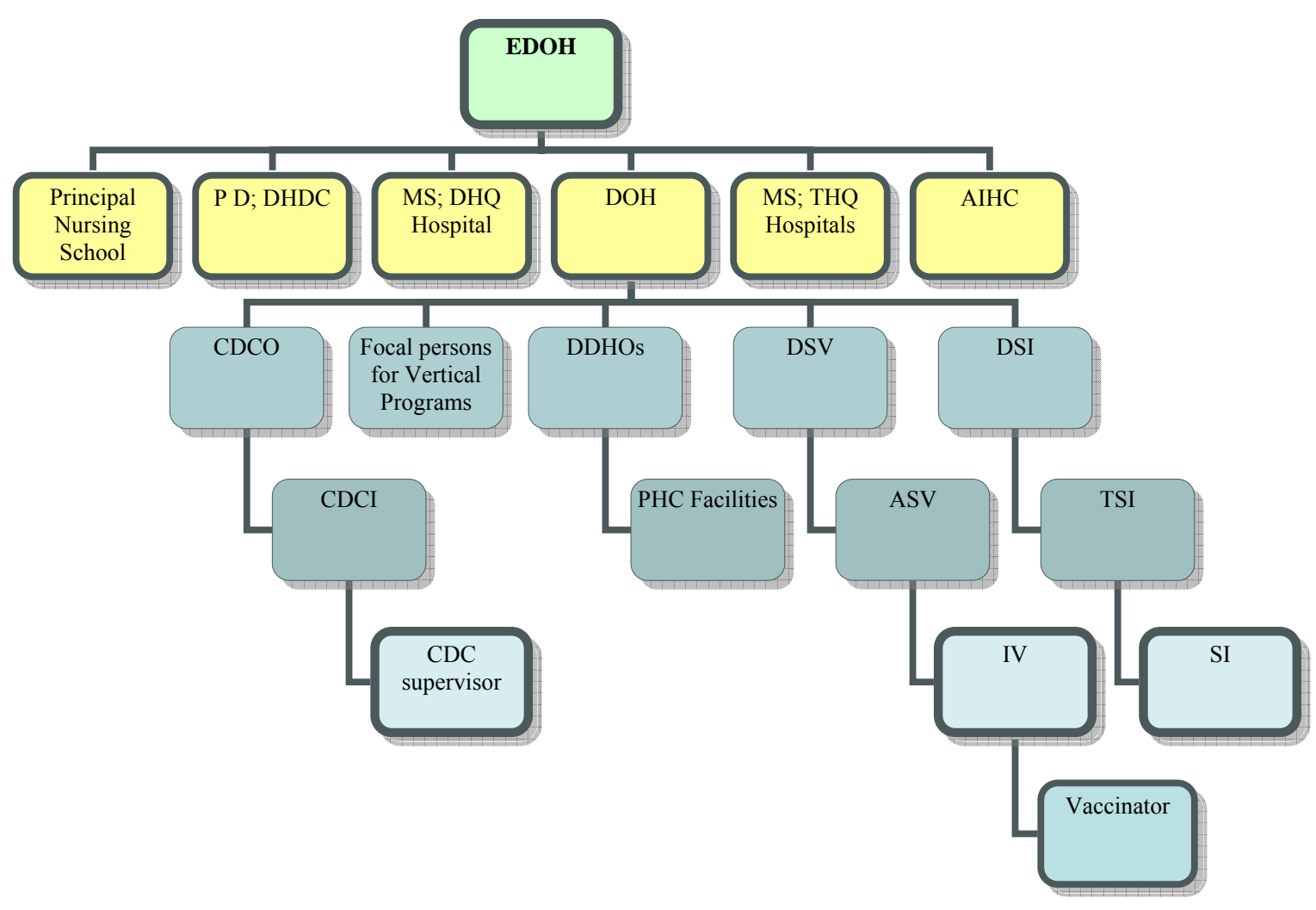


Within the district health department, there are various categories of the supervisors. The important ones include; $\mathrm{EDOH}, \mathrm{DOH}$, medical superintendents of DHQ and THQ hospitals, DDHO, DSV, ASV, CDCO/malaria superintendent, DSI, AIHC and focal persons for vertical programs (LHW, TB programs etc.). The EDOH is overall head of the district health department and is required to provide supervision and support to lower tiers of the health department. The AIHC, a senior lady health visitor, is the most relevant person to look after the $\mathrm{MNH}$ related services within the district.

The term supervision was defined in different ways by respondents. Most commonly mentioned themes or concepts included: "providing guidance," "checking," "monitoring and evaluation" and "ensuring that what needs to be done is done." Whatever its relationship to management, the term "supervision" is often met with suspicion. During the discussion the word "Supervision" was interpreted as inspection or "keeping an eye on someone" or checking the work. Most of the supervisees see supervision as "policing".

\section{Definition of "Supervision" by respondents}

"Supervision involves checking and providing guidance on performance of tasks"

"Process of getting activities done according to plan of activities"

"Giving task guidance, correcting, monitoring and evaluation"

"Leading, guiding, counseling in order to achieve desired results"

"Ensure what is to be done is done the right way"

"Coordinates services in health institutions, deploying and ensuring materials are available for the staff

to use"

"Assessment of staff motivation, evaluation of duties"

"Ensure what needs to be done is being done correctly and efficiently"

"Close look at what you are doing and monitoring the workers for the betterment of institution"

"Overseeing activities being performed including: training, service delivery, planning, implementing and feedback"

"My involvement in seeing that things are done the right way and right time"

"Supervision is: identify problems with service provider and see how you can solve them together"

"Supervision is someone planning, organizing, coordinating services and carrying out continuous

monitoring and evaluation"

"Supervision is someone charged with the responsibility"

"To ensure what needs to be carried out is carried out"

Currently, supervision is mostly crisis-oriented, and supervisory visits are generally carried out in case a need arises. It was reported that the frequency of the supervisory visits range from 10 visits each month to

One of the supervisors showed inability to accompany the study team as no vehicle/or budget was allocated for supervisory visits. 
once in 2 months. It was observed that the duration of each visit ranged from half to one hour. The reasons given for infrequent and poor quality supervision included; i) shortage of supervisors ii) confusion over roles and responsibilities iii) lack of supervisory transport iv) insufficient operational budget like petrol, traveling allowance, repair/maintenance of vehicles, etc. The other shortcomings pointed out were lack of office equipment like computers, photocopiers and communication system. In visited DHQ/THQ hospitals, MS, in general, were making infrequent supervisory visits but reported that they were holding daily meetings in their respective offices.

Although it was reported that checklists were available yet no checklists were seen during observation for supervision. No explanation was given for the failure to use the checklist. Areas of supervision are planned around specific issues or problems at the site.

All the supervisors claimed that they were providing supportive supervision but none of them assessed supervisee's skills and/or training needs to perform assigned tasks. During the supervision session, the supervisor usually observed the service provider when providing services to clients, evaluated the quality of records and examined the equipment to determine whether it was clean, adequate and in working order. Review of record was the most usual activity performed by almost all the supervisors, which gave the impression of INSPECTION rather than SUPERVISION.

It was observed that supervisory plans are neither prepared nor communicated ahead to the supervisee. After supervisory visits, feedback is given verbally, focused mainly on the maintenance of record rather than on technical issues. On the contrary, supervisees feel that they receive constructive feedback from the supervisors and visits are helpful in improving their performance. No mechanism for monitoring the advice given in previous visit and corrective action taken or otherwise is currently present.

In general, most supervisors were found knowledgeable in their respective technical areas. For example, DSV was well versed with cold chain maintenance, immunization schedule, record keeping, etc. However, none of the supervisors except LHS had formal training in supervision.

As mentioned above in methodology, the clinical care being provided in OPD of the selected health facilities was observed. Only the Gynea and Pead OPD were focused. In most of the cases, it was observed that standard protocols were neither available nor being followed. Clinical assessments of the pregnant women were just limited to history taking and incomplete clinical examination e.g. even the important parameters like BP, pulse, height, weight, temperature, was not done in most of the cases. Similarly basic antenatal laboratory investigations like urine routine examination, hemoglobin were not advised in most of the cases. Antenatal cards were not maintained.

Mostly indoor patients were not getting proper clinical care. In one of the hospital visited a patient on whom hysterectomy was performed 5 days ago. The wound of the patient was infected which was likely due to improper sterilization arrangements. In another situation, no advice was given to a patient who was discharged after D\&C. The 
above situation depicts serious deficiency of clinical care, which may be the outcome of the weak supervision.

\section{Summary Findings}

- Absence of supervisory policy

- Ambiguity in concept of supervision

- Deficient supervisory skills

- Non-availability/non-use of supervisory tools

- Inappropriate feedback mechanism

- Unplanned supervisory visits

- Unclear roles and responsibilities of various levels of supervisors

- Lack of ongoing training system for supervisors (except LHS)

- Vacant positions of supervisors

- Insufficient operational budget

- Insufficient transport for supervision

\section{Recommendations}

Moving from traditional, hierarchical supervision systems to more supportive ones requires innovative thinking, national buyin, and time to change attitudes, perceptions, and practices. The focus of this assessment was to identify gaps within the existing supervision system that could be bridged through appropriate interventions. During the course of this performance analysis, the views of many stakeholders in health sector were sought

\section{Summary of Recommendations}

- Framework for supportive supervision

- Development/adaptation of supervisory checklist

- Provision of resources for supervisory activities

- Training

regarding the existing supervision system. Many suggestions for the improvement of the supervision system as a whole were made during discussion. The recommendations being presented here are based on the suggestions made by the respondents and observations made by the study team and are grouped under four broad categories:

i. Supervisory framework;

ii. Development/adaptation of supervisory checklists;

iii. Resources; and

iv. Training. 


\section{i. Framework for supportive supervision}

Framework for supportive supervision should provide a feasible and sustainable system of supervisor/supervisee interaction using on-site and/or distant consultations. Supervision policy needs to be developed addressing the following areas:

a. Supportive supervision should be an integral part of the policy document;

b. Frequency of minimum scheduled visits should be specified e.g. every facility should be visited once in a quarter;

c. Mandatory use of supervisory checklists by all supervisors;

d. Institutionalization of feedback to the supervisee along with monitoring of agreed corrective actions;

e. Roles and responsibilities of all categories of supervisors need to be clearly defined; and

f. Adequate operational budget allocation for supervisory activities by the district governments.

\section{ii. Development/adaptation of Supervisory Checklist}

Supervisory checklist is an essential tool to implement a successful supportive supervision system as it provides the opportunity for the supervisors to comprehend the whole service provision process without missing any aspect. It may also be shared immediately with the supervisee for giving technical feedback. It serves as a monitoring tool for agreed corrective actions and facility performance assessment. At present the available supervisory checklists are fragmented and are program focused. A comprehensive checklist was developed under Health Management Information System (HMIS) in 1993 and now recently another checklist has been developed under District Health Information System (DHIS), which is currently being piloted in some selected districts. The evaluation report of DHIS including checklist is expected in about 3 month's time. If found successful, the same may be adapted for the PAIMAN districts. In case, the supervisory checklist is not approved by the government, development of comprehensive checklist is recommended.

\section{iii. Resources for supervisory activities}

Inadequate resources required for carrying out the supervisory activities at the district level was identified as one of the major constraints contributing to irregular and infrequent supervisor and supervisee interaction. Although it is out of the scope of the PAIMAN project, the district government may be pursued to provide the deficient 
resources like filling of the vacant positions of the supervisory staff, provision of adequate operational budgetary and other essential logistic support. The forum of DHMTs may play a crucial role in advocacy for securing more resources from the district government. District Health Annual Plan is another potential tool for accessing the budget for supervisory activities.

\section{iv. Training}

Although training is viewed as vital for improved supervisor's performance, very little training in supervision has been conducted within the health sector. The development of a supervision-learning package will be welcomed by supervisors and service providers at all levels within the district. International and national experiences clearly indicate that the onsite training has the most lasting effect on the quality of supervision and ultimately the quality of services. It is recommended that training may be combination of class-room and on-job training supplemented with periodic refresher trainings. Participant will recap the knowledge of the services to be supervised and will learn the skills of using supervisory checklists for the specific services to be supervised. All types of training methods including lectures, interactive sessions, role play, exercises and assignments will be used to impart knowledge and skills of core competencies. Based on the findings, the areas recommended to be addressed in the training package, are described in the below paragraphs:

a. Introduction and concepts of supportive supervision: A specific module will be developed to impart the clear concept of the supportive supervision in contrast to traditional inspection oriented supervision. Health supervisors will be motivated to adopt an interactive, objective oriented, problem solving and ongoing system of supervision. This module will also cover the salient features and principles of supportive supervision including onsite training.

b. Supervision core competencies: Core competencies will be covered in multiple modules and each module will cover the specific area of service provision to be supervised as under:

i. Planning: Planning is a basic skill for better supervision but often supervisors do not plan ahead their supervisory activities. Although many supervisors lack standardized tools or checklists to guide them during their duties, many develop checklists of their own. Some supervisors do use departmental reports and records for planning supervision and many do not use information at their disposal. Some plan for supervision on a daily basis, while others respond to requests or needs from their supervision sites. Generally, planning is crisis-oriented and improvised by individuals. Clearly, supervisors would benefit from learning how 
to become better planners, which would in turn help to standardize the supervision procedures.

ii. Staffing: During the supervisory visits, the supervisors face many challenges regarding staffing issues. They will be trained in dealing with motivational issues such as facilitating teamwork, job productivity, job satisfaction, conflict management and performance appraisals.

iii. Onsite training of supervisees: This module will focus on how to impart onsite training to their supervisees. It would address skills such as providing guidance, coaching. Moreover they will also acquire knowledge and skills in preparing/ organizing different types of training and following up trainees.

iv. Information and communication: Usually the supervisors are not aware of the importance of information for supervision although it is considered necessary to effectively carryout supervisory activities such as planning, report writing skills and use and sharing of information including feedback to supervisee.

v. Supervision of Logistic: The availability of essential drugs is perceived by the communities as one of the indicators of the quality care. This module will cover the supervisory skills necessary for supervision of drugs and other supplies management at facility and community level.

vi. Skills for utilization of supervisory checklist: The trainees would be provided hand on training on how to use the supervisory checklist. Participant will also practice filling of checklist in the classroom and in the field.

There will be a four days classroom (duration will be adjusted after pre-testing) followed by on-job training spread over four months. The detailed training program will be discussed later on at an appropriate place. 


\section{Implementation Strategy}

In order to translate the above-mentioned recommendations into action, a comprehensive supportive supervision model is being proposed. This model is derived from participatory supervision model implemented in Thailand and Video-aided Model of supervision in Jerusalem. These models have been adapted to suit the local environment.

\section{COMPREHENSIVE SUPPORTIVE SUPERVISION MODEL}

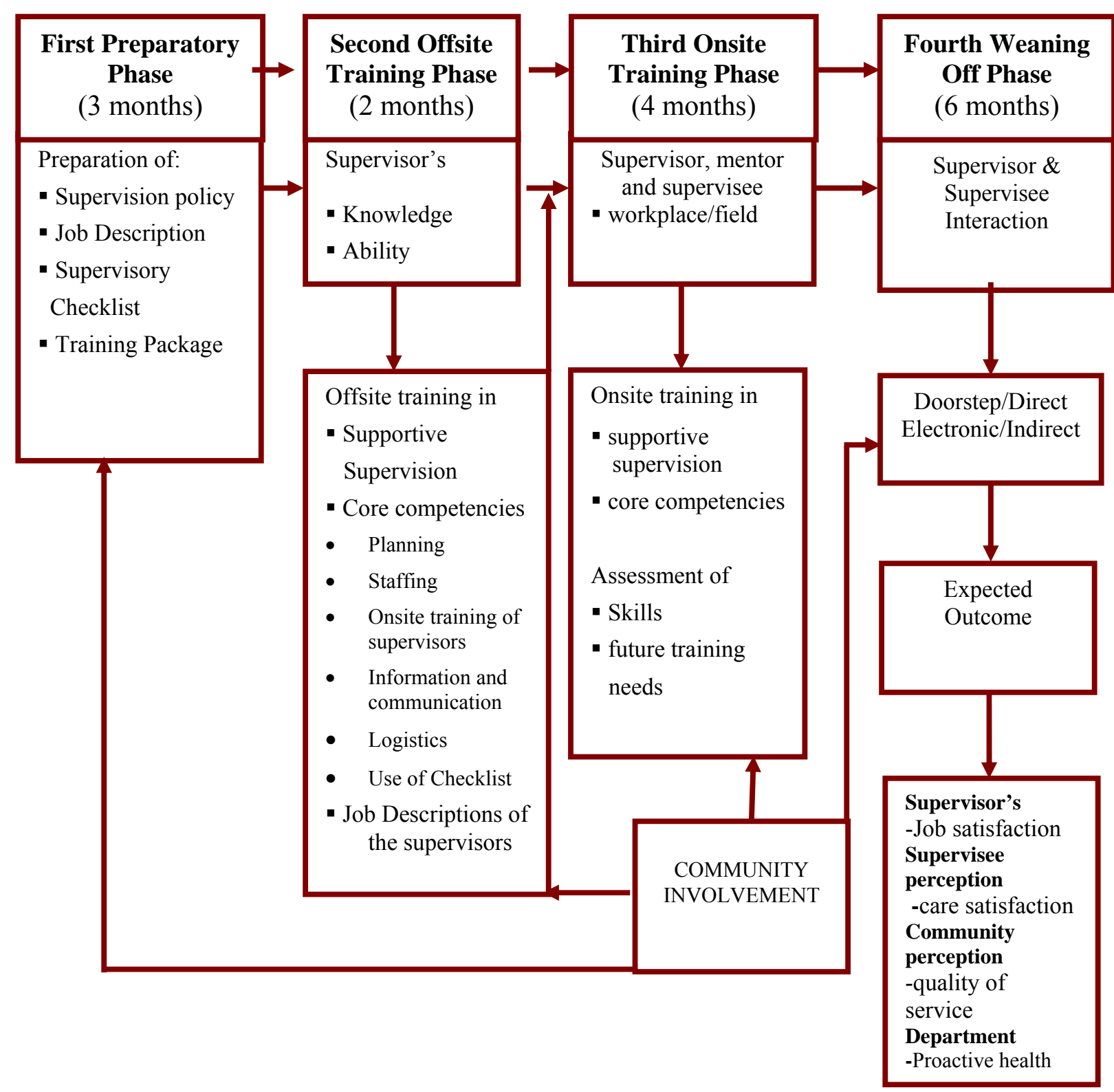


The model contains three prongs i) Direct supervision ii) Indirect supervision and iii) community involvement. This model will be implemented in four distinct phases; first/preparatory phase, second/off-site training phase, third/on-site training phase and fourth/weaning off phase. The main activities and characteristics of each of these four phases are detailed as follows:

a. First- preparatory phase: In this phase government will be assisted in preparation of the supportive supervision policy, job descriptions of various categories of supervisors, development/adaptation of supervisory checklists. Training package for supervisors will also be developed keeping in view the gaps identified during the assessment and future needs. This phase will last for about three months.

b. Second-offsite training phase: During this phase all supervisors will be given four days class room training, focusing on the following areas:

- basic and essential information on the definition, concept, principles, characteristics of supportive supervision;

- core competencies;

- job description of the supervisor;

- protocols enabling them to have contact with supervisee in their workplace;

- plans for work and onsite training of the supervisee

- The district supervisors of various categories will be provided training in batches; each training will last for four days. Community involvement will be ensured through existing institutional arrangements under Local Government Ordinance 2001. One representative of District Nazim, who is member of DHMT will also be trained with other supervisors and will participate in supportive supervision activities. This phase will spread over two months.

c. Third-onsite training phase: On completion of second phase supervisors will be supported by a mentor. It is proposed that $\mathrm{EDOH}$ and $\mathrm{DOH} / \mathrm{DDHO}$ may act as mentor(s) in their respective districts. The mentor will constantly 'train' the supervisor in this phase. The mentor will accompany supervisor during their visits to supervisees. At least TWO supervised visits will be conducted by each of the supervisors during this phase. The mentor, supervisor and supervisee will be facilitated to have more frequent interaction through modern methods of communication. In order to conclude this phase the supervisor and mentor will meet to review the overall process and the supervisor's progress, decide whether the supervisor has achieved competency in the required skills and assess implications of this in respect of future training needs. Depending on the circumstances the formal assessment can be undertaken in a supervisee's work place. This phase may be expanded if 
assessed that more training is required. This phase will spread over four months.

d. Fourth-weaning off phase: In the weaning off phase, supervisor will make visits to supervisee's workplaces independently i.e. without mentor, however, technical support will be provided as $\&$ when required. At all times during this phase, the supervisee will have the means to be able to contact the supervisor by phone/email. This phase will last for six months, at the end of which an evaluation will be made to assess effectiveness of the model and to suggest modifications, if required. 


\section{Annexure}

Annexure 1

\section{Literature Review}

1. Zimbabwe ${ }^{3}$ : A study in Zimbabwe under Quality Assurance Project indicated that the supervisors' weakest areas were continuity of supervisory visits, being proactive, and engaging in joint problem solving with front-line providers. Building on this formative study, a skill development program was launched to improve the supervisory skills and supervisor-provider interaction which resulted in improvement of service delivery by the service providers.

2. Indonesia ${ }^{4}$ : A training program on supervisory skills in Indonesia involved three groups: Group 1 received one week training only; group 2 received the training and implemented the self-assessment for 16 weeks following the training; and group 3 received the training and implemented both the self-assessment and peer review for 16 weeks. The results showed that one week training-only group though had strong short term impact, yet lost about half of its gain in both facilitative and informative communication after 16 weeks. While the other two groups maintained their gain in facilitative communication although they lost about half the gain in informative communication. These results suggest that self-assessment and peer review interventions are effective strategies for reinforcing training in facilitative communication.

3. Uganda ${ }^{5}$ : The Uganda $\mathrm{MOH}$ has implemented the development of a national supervision system as a part of the general health sector program (Uganda $\mathrm{MOH}$, 1999). The national supervision strategy included: the development of national guidelines, the development of a supervision schedule, a plan to obtain a steady source of funds, the involvement of community leaders, training and advocacy programs, and the application of a cascade approach (i.e., center to district, district to facility, facility to community). Areas to be supervised include: funds utilization, progress on national indicators and sector development in relation to macro economic development.

\footnotetext{
${ }^{3}$ Kim, Y.M. et al., The Quality of Supervisor-provider Interactions in Zimbabwe, Operations Research Results 1(5), USAID Quality Assurance Project, Bethesda, Maryland, 2000

${ }^{4}$ Young M, Fiti P et al. Self Assessment and Peer review, improving Indonesian Service Providers Communication with clients. International Family Planning perspectives; Vol. 26 Number 1, 2000.

${ }^{5}$ Uganda Ministry of Health's Quality Assurance Program. 1999. National Supervision Guidelines. Uganda Ministry of Health/Quality Assurance Program: Kampala, Uganda.
} 
4. Tanzania": According to a study "District supportive supervision following health sector reform in Tanzania" published in 2002 (Dohlie, MB. et al), the District Health Management Team in Tanzania involves an integrated supervision team and uses a matrix to conduct and monitor supervision. Supervision is now more frequent and health workers use it as an opportunity to solve problems. Since this system has been adopted, health workers have noticed a significant improvement in supervision. Supervisory contact is more frequent; problems are being solved, and on-the-job training is being conducted. Supervisory visits have become an opportunity for health workers to solve problems and learn additional skills. Health workers are no longer afraid to address challenges and are able to work with the DHMT to resolve them.

5. Thailand ${ }^{7}$ : In 1991, in Thailand, two models were implemented at two primary care units in one district over a six-month period. The first model involved supervisors from the district level, with the full participation of health officers at the sub-district level. The second model was designed with the addition of community involvement in the supervision process. Before implementing the models, the district supervisors attended a retraining course to enhance their supervisory knowledge and ability. The study indicated that after the intervention, both supervisory models appeared effective in terms of clients' perceived service quality and satisfaction with care. However, the second model, which allowed the community to participate in the supervision process, achieved better results.

6. Kenya ${ }^{8}$ : In 1999, Engender Health adapted COPE (Client Oriented Provider Efficient) services tools for use in child health services in Kenya and Guinea. The COPE ${ }^{\circledR}$ philosophy is one of participation, teamwork, ownership, and shared responsibility. There is a large focus on clients, staff development, capacity building, and supervisor engagement. COPE $®$ is a process with a set of tools for health care staff to continuously assess and improve quality of care. It is built on a framework of client rights, staff needs, and consists of the following four tools:

- A self-assessment guide (one for each of the client rights and staff needs)

- A client interview guide

- A client flow analysis

Eight study sites were selected and COPE approach was implemented with eight control sites for 15 months. Results show that participants felt supervision was better

\footnotetext{
${ }^{6}$ Dohlie, MB. et al., .Empowering Frontline Staff to Improve the Quality of Family Planning Services: A Case Study in Tanzania., Responding to Cairo, Case Studies of Changing Practice in Reproductive Health and Family Planning, Population Council, New York, 2002.

${ }^{7}$ Evaluation of Participatory Model of Supervision, in Thailand. Ministry of Public Health Thailand; 1999

${ }^{8}$ Bradley, J et al., COPE for Child Health in Kenya and Guinea: An Analysis of Service Quality, Engender Health, New York, 2002
} 
than before and that supervisors were practicing their new skills and were following up on problems identified.

7. Honduras ${ }^{9}:$ A reproductive health, nongovernmental organization (NGO) in Honduras adopted a strategy to improve supervision and service delivery while reducing costs. The group looked at performance issues and developed a supervision system to address them. A comprehensive approach was adopted where everyone was responsible. This approach addressed quality assurance program, management information system, performance planning and evaluation, performance recognition system, holding meetings, field visits and continuous training,. Performance goals were achieved, service quality improved, and client satisfaction increased.

8. India ${ }^{10}$ : In early 2001, the Government of India, Department of Health and Family Welfare, along with the Children Vaccine Program at Program for Appropriate Technology in Health (PATH), initiated a project to improve routine immunization in the state of Andhra Pradesh (AP). As part of their commitment to improving supervision, the government opened six new posts for supervising supervisors who were responsible for three to four districts with a combined population of about 10 to 12 million people. This was coupled with data tracking system, community involvement and outsourcing of supervision. According to the document the process is underway and the initial results are encouraging.

\footnotetext{
${ }^{9}$ Marquez, Kean. Making Supervision Supportive and Sustainable: New Approaches to Old Problems, Maximizing Access and Quality Initiative, MAQ Paper No. 4, USAID, Washington, DC, 2002. Available online at www.maqweb.org/maqdoc/MAQno4final.pdf

${ }^{10}$ Government of India, Child Health Division, Department of Family Welfare, Ministry of Health \& Family Welfare, Introduction of Hepatitis B Vaccine in the Universal Immunization Program: A Handbook for Program Managers \& Medical Officers, 2002.
} 


\section{Review of Various Supervision Models}

\section{The 7 Eyed Supervision Model $^{11}$}

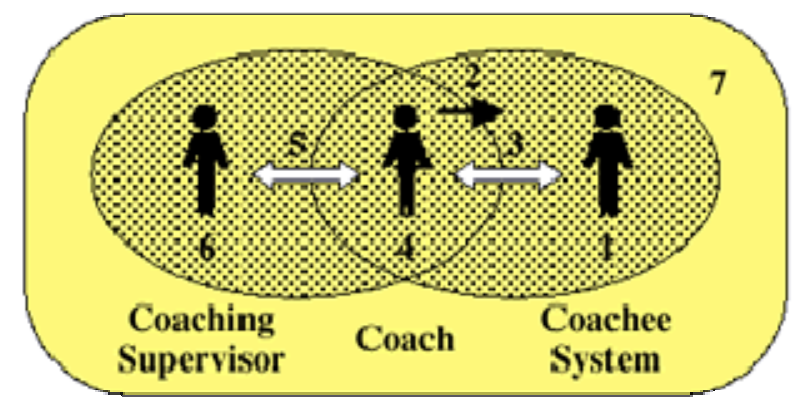

Originally developed Peter Hawkins and Robin Shohet, for use with psychotherapists and counselors. It specifies the 7 areas that supervision can focus on:

1. The Supervisee/Supervisee System: The focus is on the supervisee situation - the problem the supervisee wants help with, how they present the issues and the choices that they are making;

2. The Supervisor's Interventions: The focus is on the interventions the Supervisor/supervisor made, how and why they made them, and what else they might have done;

3. The Relationship between the Supervisor and Supervisee: The focus is on neither the Supervisor nor their Supervisee but on the conscious and unconscious interactions between the two of them so that the Supervisor develops a better understanding of the dynamics of the Supervising relationship;

4. The Supervisor: The focus is on the Supervisor's own experience as an instrument for registering what is happening beneath the surface of the Supervisee system;

5. The Parallel Process: The focus is on what the Supervisor has absorbed from the Supervisee system and how it may be playing out in the relationship between Supervisor and supervisee;

6. The Supervisor's Self-reflection: The focus is the supervisor's "here and now" experience with the Supervisor and how this can be used to shed light on the Supervisor/Supervisee relationship; and

7. The Wider Context: The focus is on the wider organizational, social, cultural, ethical, and contractual context within which the supervision is taking place.

11 Supervision in the Helping Professions" by Peter Hawkins and Robin Shohet, ISBN: 0335201172. 
The value of this model is that it maps the areas that supervision can focus on, making it easier to ensure that we have covered the ground. And by changing the labels in the diagram above, we can equally well use it as a model for what we can focus on in a supervising session.

\section{Unique Model of Guided Supervision ${ }^{12}$}

The Unique Model of Guided Supervision was developed in 1996, defined as a set of Systems of Information and Analysis, philosophy of work, strategies, politics and supervision procedures, with emphasis in the risk evaluation to guide and dosage the in site supervision which lays in an uniform system of qualification, based on a set of indicators and qualitative criteria, which with a determined weighting, summarizes in one only indicator the General Situation of the Entity evaluating its performance in five fundamental areas: Management, Quality of Assets, Liquidity, Profitability and Capital, named System of Qualification of Supervised Entities (SUPER, by its Spanish acronym). The elaboration and ongoing function of this model needed to realize a deep organizational restructuring that will allow us to adapt to the needs of the environment and to reach the purposes of the model.

\section{Video-Aided Supervision Model $^{13}$}

The Video-aided Supervision model was developed at the Early Childhood Graduate Program in the School of social work, the Hebrew University in Jerusalem. It is part of an ongoing endeavor, supported by the Haas Fund, to incorporate new norms of in-service training for caregivers working with infants and toddlers, and to create new standards of caregiver-child interactions in Israeli early childhood daycare settings.

The supervision model is based on a humanistic, client-centered and reflective approach to supervision. By focusing on the supervisee choices, her interests, her motivations and needs during the supervision sessions, the Video-aided Supervision model promotes a sense of autonomy and professional growth.

Supervision sessions are intensive (biweekly) and individualized, supported by (less frequent) group supervision. The video medium is introduced to the child-care settings for two purposes: child observation and caregivers' self-observation. Using a small camcorder, a target-child is filmed during daily activity at daycare. The camera focuses for approximately ten minutes on the child's behavior, interactions (or lack of interaction), communication signals and emotional expressions. The tapes are viewed later during regular, ongoing supervision sessions that are based on joint viewing with a skilled supervisor.

12 Superintendencia de Bancos . Guatemala, 2006 available at http://www.sib.gob.gt/en//nformacion-General/mod-supervision.asp
13 Lihi Gatt, Early Childhood Graduate Program, School of Social Work Hebrew University in Jerusalem, Israel. 
The Video-aided Supervision model recommends that at first stage of supervision the caregiver/supervisee herself will film the children in her care, thus beginning with child observation only, and proceeding to caregiver's self observation after basic trust and supervisory relations have been well established.

Video child-observations sensitize the caregivers to individual children, facilitating a process of deep viewing and tuning into the child's daily group experience. The video allows the caregivers to focus on challenging children (i.e. those having trouble to adjust to group care, exhibiting internalizing and externalizing behavior, and demonstrating low social competence). A dynamic process of observation occurs as the caregiver views the tapes again and again, thus gaining new insights into the child's overt behavior, identifying his subtle signals and acknowledging his unique communicative pattern. Video self-observation enhances the caregivers' self-awareness to her own response patterns towards different children, and helps her recognize and make use of her strengths and abilities.

The joint viewing of the tapes together with a skilled supervisor promotes affective learning, full of insights and emotional engagement. It produces a profound cognitive, emotional and behavioral change, as the caregiver re-defines her attitude towards specific children and re-considers her developmentally appropriate practice.

\section{Self Model of Training and Supervision ${ }^{14}$}

A central component of the Georgia State University Counseling Center training program is a focus on developing the "person of the therapist" and "the use of self" as an instrument of change. Use of Self is defined as a process through which therapists (and trainees) learn how to use their personal (emotional and cognitive) reactions and knowledge of self in order to: 1) inform conceptualizations of their client's struggles and 2) create a therapeutic relationship that is collaborative and conducive to corrective relating with the aim of overcoming difficulties and facilitating personal growth.

Although supervisors represent a variety of theoretical orientations, (e.g., object relations, interpersonal, cognitive behavioral, humanistic, feminist and integrationist), a supervision model is used that looks at reactions to clients/supervisors and their reactions too and how to utilize this information in the work with clients.

This model, therefore, expects trainees to invest in synthesizing effective use of self with clinical skill acquisition through supervised experiential learning and formalized training. Because of this philosophy, supervisors commonly prompt trainees to self-reflect and, often, this does result in an implicit expectation that some exploration of the trainee's personal experience (as triggered in her/his clinical activities or in the supervisory relationship) will be open for discussion between supervisor and trainee in their working relationship. The choice of how much personal history to share, however, is up to the

14 Wells, M \& Bell Pringle, V. 2004, Use of self in supervision model: Relational, ethical \& cultural issues 
trainee, and trainees are not penalized for asserting their best assessment of an appropriate level of disclosure regarding such personal history. The emphasis is on the willingness of the trainee to discuss his or her reactions to clients and/or the supervisor in addition to exploring the impact of personal issues on his/her clinical work.

\section{Best Practice Model for Supervision and Buddying ${ }^{15}$}

This Best Practice Model for Supervision and Buddying has been developed to help support the case for the endorsement of a Traineeship for Community Care Work and to seek a variation in the Department of Education and Training's standard Traineeship 'Supervision' requirements.

The Supervision and Buddying Model for the Community Care Traineeship has been developed to ensure that:

- New Apprenticeship System (NAS ie. Apprenticeships and Traineeships), as operated in WA by the State Department of Education and Training in conjunction with the Commonwealth, has an acceptable variation in its supervision and mentoring requirements that have been designed to optimize the acquisition of the required competencies;

- Trainees are protected by the incorporation of appropriate supervision and buddying protocols and safeguards for the on-the-job component of the Traineeship which are designed to optimize their acquisition of the required competencies; and

- Quality care standards within the Community Care sector are maintained and enhanced by the operations of the Traineeship, and the recruitment of more workers with appropriate qualifications to its workforce.

\section{Model for Clinical Supervision in Allied Health ${ }^{16}$}

Stamm discussed clinical supervision through a telehealth model for rural placements in psychology and other allied health professions. She noted that clinical sites are staffed with a supervisory-level participating investigator, four therapists, two case managers, and one assessor. In addition, each site has a research assistant with training in both psychology and technology. Each site provides a 30-week course of therapy to patients along with supervision. Ongoing training and supervision is required to standardize the psychotherapy and assessment from site to site. Remote supervision of the 80 clinicians is provided by four clinical supervisors (one for each therapy condition, one for case management, and one for assessment). The clinical teams have monthly group teleconferences (audio or, when necessary, video) with weekly individual telephone

15

Community Care Work Traineeship 2003, State Department of Education and Training, Western Australia

16 Stamm B. Telehealth in a clinical trial: Remote clinical and administrative supervision. In R. Gleuckauf (Chair), Telehealth for persons with chronic medical conditions - program evaluation developments. Presented at the 106th Annual Convention of the American Psychological Association, San Francisco, August, 1998. Available at http://www.darthmouth.edu/ csp420/proffesional 
supervision and daily or as needed e-mail supervision. Supervisors and the clinicians have duplicate copies of tapes of the previous week's clinical encounters to facilitate supervision.

Considering the supervision component only, the use of telehealth for supervision included over 20,000 e-mails, 1,800 hours of individual phone supervision, 500 hours of group phone consultations, 450 secured fax information forms, 10,000 hours of audio taped sessions, and 500 hours of psychotherapy videotape. Communications were catalogued in a searchable, analyzable database. Routine analysis of the information in the database supports the activities of supervision.

\section{Participatory Supervision Model $^{17}$}

The Participatory Supervision Model was developed in 1991. However, many supervisors lack supervisory knowledge and skills. This model focuses on enhancing the health promotion capacity of health officers in primary health care units. The model was implemented at a PCU in one semi-district, Chiang Mai Province, over a six-month period. The model involved supervisors from the district level, with the full participation of health officers at the sub-district level with the addition of community involvement in the supervision process. Before implementing the model, the district supervisors attended a retraining course to enhance their supervisory knowledge and ability. Both before and after the intervention, the PCU health officers appeared to have good and comparable job satisfaction levels. After the intervention, the supervisory model appeared effective in terms of clients' perceived service quality and satisfaction with care, among those who utilized the PCU. The qualitative findings suggested that the involvement of health officers caused a rapid change and improvement after the supervision. The involvement of the community helped the community itself to identify problems and formulate alternatives to meet the community's needs. To ensure successful implementation, several issues, such as the supervisor's knowledge and ability, health officer workload and supervisory communication skills, need to be improved.

\section{Developmental Model of Supervision ${ }^{18}$}

The medieval developmental model is the most frequently referred to developmental model.

Stage 1: The Supervisee is an Apprentice: During this first stage the emphasis is upon skills development and understanding theory and it's application. Building up the confidence and self-belief of the supervisee.

\footnotetext{
${ }^{17}$ Sennun P, Suwannapong N, Howteerakul N, Pacheun O. Participatory supervision model: building health promotion capacity among health officers and the community. Rural and Remote Health 6 (online), 2006: 440. Available from: http://rrh.deakin.edu.au

18 Gail D. Dixon, M.A., CAPP, NIDA Project Manager Southern Coast Addiction Technology Transfer Center (SCATTC), 2002
} 
Stage 2: The supervisee is a journeyman craftsman: How can I help this particular client. The supervisee is starting to make his / her work a reflection of themselves. Issues often need to be dealt with during this phase.

Stage 3: The supervisee is an independent Craftsman. A qualified practitioner beginning to see the therapy in it' s wider context and to deal with the relationship process.

Stage 4: The supervisee is a master craftsman. The supervisee is an experienced practitioner with the ability to self evaluate in the wider context.

Six stages of development in the learning process:

In this model the first three areas are seen as beginning stages, with the second three stages as being advanced. This model is based on an article by Bruce Loria 1983 TAJ, in which he quotes early educational works.

Basic:

1. Knowledge of theory.

2. Understanding of theory.

3. Application of theoretical concepts.

Advanced:

4. Analysis of the component parts of the theory and application relevant for each client.

5. Synthesis: the bringing together in a unique way the therapists own application and understanding of theoretical concepts.

6. Evaluation, self-evaluation in the wider context.

IX. Gordon Law's model ${ }^{19}$ - A fun quick group supervision model:

The story / problem is briefly related to the group by the supervisee. Each member of the group asks the supervisee a question, which remains unanswered.

Each person in the group then formulates a hypothesis regarding the questioner's reason for asking the question. This hypothesis is then related to the supervisee, without comment by them. The supervisee then goes through the questions and hypothesis one by one, saying which is most useful / least useful and why.

${ }^{19}$ Dave S, Gordon Law's Model, 2006 available at http://www.ta-psychotherapy.co.uk/supervision.htm 


\section{A) Checklists of observations for supervisory visits}

\begin{tabular}{|l|l|}
\hline \multicolumn{1}{|c|}{ Items } & Observation \\
\hline Availability of Checklists & \\
\hline General observation & \\
\hline Discussion & \\
\hline $\begin{array}{l}\text { Analysis } \\
\bullet \text { Strengths } \\
\bullet \text { Weaknesses }\end{array}$ & \\
\hline Feedback on merit & \\
\hline $\begin{array}{l}\text { Support for improvement } \\
\text { through education }\end{array}$ & \\
\hline $\begin{array}{l}\text { Monitoring of previous visit } \\
\text { and corrective action }\end{array}$ & \\
\hline
\end{tabular}

\section{B) Guide questions for discussion}

\begin{tabular}{|l|}
\hline Definition and concept of supervision \\
\hline Understanding of core tasks \\
\hline Tools for supervision \\
\hline Technical competence of supervisors \\
\hline Frequency of visits \\
\hline Use of information collected during visit \\
\hline Feedback reports \\
\hline Monitoring of corrective action \\
\hline Improvement in performance after visits \\
\hline Receipt of adequate guidance in the past \\
\hline Staff grievances \\
\hline
\end{tabular}

\section{C) Checklist for the review of record}

\begin{tabular}{|l|l|}
\hline \multicolumn{1}{|c|}{ Records } & Observation \\
\hline Written schedule of visits & \\
\hline Communicated ahead & \\
\hline Filled in supervisory checklists of & \\
\hline
\end{tabular}




\begin{tabular}{|l|l|}
\hline \multicolumn{1}{|c|}{ Records } & Observation \\
\hline previous visits & \\
\hline Visits or tour diaries of the supervisors & \\
\hline $\begin{array}{l}\text { Use of information collected during } \\
\text { visits }\end{array}$ & \\
\hline Feedback reports to the supervisee & \\
\hline Monitoring of corrective action & \\
\hline $\begin{array}{l}\text { Subsequent visits and improvement in } \\
\text { performance as compared to the } \\
\text { previous visit }\end{array}$ & \\
\hline
\end{tabular}

\section{D) Checklist for clinical observations}

\begin{tabular}{|c|c|}
\hline Areas & Observations \\
\hline Antenatal & \\
\hline $\begin{array}{l}\text { History } \\
\text { - } \text { Card present (last visit) } \\
\text { - } \text { Age } \\
\text { - } \text { Gravida } \\
\text { - } \text { Week of pregnancy } \\
\text { - Chronic diseases } \\
\text { - Previous delivery } \\
\text { - Any complaint } \\
\text { o History of fever } \\
\text { o Backache } \\
\text { o Discharge } \\
\text { - Palpitation and Breathlessness }\end{array}$ & \\
\hline $\begin{array}{l}\text { Physical examination } \\
\text { - Height } \\
\text { - Weight } \\
\text { - Anemia } \\
\text { - BP } \\
\text { - Edema of feet } \\
\text { - Height of fundus } \\
\text { - Outlet } \\
\text { - Position of the baby } \\
\text { - Signs of bleeding or discharge } \\
\text { - Fetal heart sounds } \\
\text { - Breast examination }\end{array}$ & \\
\hline $\begin{array}{l}\text { Blood Examination } \\
\text { - Blood grouping } \\
\text { - Blood Complete Exam. }\end{array}$ & \\
\hline Urine examination & \\
\hline
\end{tabular}




\begin{tabular}{|l|l|}
\hline \multicolumn{1}{|c|}{ Areas } & \multicolumn{1}{|c|}{ Observations } \\
\hline - Albumen & \\
- Sugar & \\
\hline Medical advice \& Health education & \\
regarding diet, personal hygiene, rest, & \\
mental health, regular antenatal & \\
checkup, preparation of breast feeding, & \\
precautionary measures about care & \\
during pregnancy \& confirmation of & \\
next visit & \\
\hline Iron \& Multivitamin tabs & \\
\hline Referral arrangement in emergency & \\
\hline Care during delivery & \\
\hline Assessment of the case whether normal & \\
or otherwise (referral) & \\
\hline Observation of 5 Cs & \\
Clean & \\
- Hands & \\
- Place & \\
- Perineum & \\
- Instruments & \\
- Cord & \\
\hline Room temperature & \\
\hline Family planning advice & \\
\hline Care of neonate & \\
- Apgor Score & \\
- Cleaning of mouth and throat of & \\
- infant & \\
- Reeping sign & \\
- Respiratory checkup & \\
- Breastfeeding within half an hour & \\
- Wrapping according to season & \\
- Weighing of baby & \\
- Checking for deformities & \\
\hline Postnatal Care & \\
- Fever (temperature) & \\
- Smell (sepsis) & \\
- Physical exercise for rehabilitation & \\
\hline Neonatal \& Child Care & \\
- Continuation of breastfeeding & \\
\hline
\end{tabular}


Annexure IV

\section{List of Experts Consulted}

1. Dr. Fazal Mehmood, EDOH, Multan

2. Mr. Naseem Ahmad Khan Senior Planning Officer, Health Department, Government of the Punjab, Lahore

3. Dr. Ahmad Affifi, Director Admin, office of the DGHS Punjab, Lahore

4. Dr. Dhani Buksh Thebo, EDOH Dadu

5. Dr. Muhammad Hassan, EDOH Buner

6. Dr. Naseer Ahmad, Program Director DHDC, Jhelum

7. Dr. Ameer Zahir, District Coordinator LHW Program, Buner

8. Dr. Sajjad Sarwar, Incharge RHC, Choti Zerin, DG Khan

9. Dr. Manzoor Ahmad, HMIS Coordinator, Dadu

10. Dr. Muhammad Hayyat Ronjho, HMIS Coordinator, Lasbela

11. Dr. Muhammad Ashraf Majrooh, Assistant Professor Community Medicine Depart, Allama Iqbal Medical College Lahore

12. Professor Amanullah Khan, Director, College of Physicians and Surgeons Pakistan, Lahore

13. Professor Dr. Fehmida Jalil, Executive Director Contech International Health Consultants, Lahore

14. Dr. Naeemuddin Mian, CEO, Contech International Health Consultants, Lahore

15. Dr. Muhammad Anwar Janjua, Executive Director Contech International Health Consultants, Lahore

16. Dr. Muhammad Ayyub Sulehriya, Executive Director Contech International Health Consultants, Lahore

17. Dr. Qamar Salman, Deputy CEO, Contech International Health Consultants, Lahore

18. Dr. Ahmad Nadeem, Public Health Specialist, Contech International Health Consultants, Lahore

19. Dr. Muhammad Ashraf Ch, Public Health Specialist, Contech International Health Consultants, Lahore

20. Dr. Shahid Ahmad, Public Health Specialist, Contech International Health Consultants, Lahore 


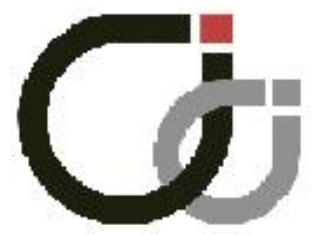

\section{Contech International}

\section{Health Consultants}

\section{JSI}

JSI Research \& Training Institute, Inc.

CA \# 391-A-00-05-01037-00 project is funded by the United States Agency for International Development and implemented by J SI Research \& Training Institute, Inc. in conjunction with Aga Khan University, Contech International, Greeenstar Social Marketing, J ohns Hopkins University/CCP, PAVHNA, The Population Council, Save the Children USA 